\title{
(2) OPEN ACCESS \\ Insights from behavioural economics for effective leadership during the pandemic
}

\author{
Janet Schwartz 두, Aline Holzwarth
}

Center for Advanced Hindsight, Duke University, Durham, North Carolina, USA

\section{Correspondence to} Dr Janet Schwartz, Duke University, Durham, NC 27708, USA; janet.schwartz@duke.edu

Received 19 October 2020 Revised 22 January 2021 Accepted 3 February 2021

Check for updates

(C) Author(s) (or their employer(s)) 2021. Re-use permitted under CC BY-NC. No commercial re-use. See rights and permissions. Published by BMJ.

To cite: Schwartz J,

Holzwarth A. BMJ Leader

Published Online First:

[please include Day Month

Year]. doi:10.1136/

leader-2020-000405

\section{ABSTRACT}

The novel coronavirus and related COVID-19 pandemic have introduced unprecedented public policy and health challenges. In addition, healthcare consumers and workers face poor coordination by government and health officials, who lack consensus on critical elements that range from understanding risks and managing uncertainty to crafting responses that could help safely guide their constituents. As such, healthcare organisations increasingly look to their own leaders to successfully steer patients and workers through the crisis. Insights from behavioural economics can help healthcare leaders communicate information to their constituents as they make important and difficult decisions under situations of risk and uncertainty. Understanding how people interpret information about risk and uncertainty, and how they might respond to strategies that help them contextualise this information through defaults and social norms, can lead to better outcomes in patient health, employee safety and well-being and overall health system utilisation. Leaders who effectively leverage these insights may chart a clearer path towards desirable short-term and long-term organisational outcomes.

On 27 July 2020, Alphabet Chief Executive Officer Sundar Pichai announced that Google's worldwide offices would remain closed until at least July 2021. While helping to prevent the spread of the novel coronavirus by moving the bulk of operations online, the move further inoculated employees against one of the virus's most insidious threats: uncertainty. With remote work firmly in place, Googlers were empowered to make decisions about schooling, caregiving and housing without having to weigh the unknowable chances of a sudden pivot back to schedules governed by commuting and office time. By eliminating some uncertainty, Google set a clear standard in a sea of indecision and moving landmarks.

Companies like Google had the fortunate ability to move online, as much of their work can be done remotely. In healthcare, too, the pandemic has accelerated the adoption of remote care models that are both effective and convenient. Although we do not yet live in a world where blood samples can be extracted in patients' homes or surgeries can be performed remotely, we can nevertheless reduce the impact of the uncertainty and risk that plague today's healthcare environments. Such efforts can guide people towards safe and beneficial behaviours that range from adopting non-pharmaceutical interventions (NPIs) to seeking necessary care.
This paper draws on insights from behavioural economics to help healthcare leaders guide their patients and employees through these times of risk and uncertainty, thereby increasing individual decision confidence. ${ }^{1}$ Healthcare leaders can start by communicating the known or unknown risks and outlining the steps their organisations are taking to understand and mitigate them. This will help people properly weigh the attributes involved in important trade-offs, or nudge them towards better choices by incorporating smart defaults and conveying positive social norms. By understanding the biases that shape decision-making, healthcare leaders will be better positioned to steer their constituents towards healthier choices during the pandemic and beyond. By managing uncertainty, risk perception and confidence among patients and healthcare workers, leaders can guide their organisations to better outcomes, ranging from patient health and employee safety to overall health system costs.

\section{DECISION-MAKING RESEARCH HIGHLIGHTS THE NEGATIVE CONSEQUENCES OF UNCERTAINTY}

A key focus of behavioural economics explores how people make decisions under uncertainty, and the inherent discomfort presented by uncertain situations. ${ }^{2}$ Unlike its more calculable cousin, risk, uncertainty refers to situations where people do not know the outcomes or the probability that they will occur. Uncertainty is common in medical decisionmaking, where the probabilities associated with detecting and treating disease are often unknown. ${ }^{3}$ Like risk, the uncertainty associated with medical decisions is particularly unpleasant because of the human propensity to imagine negative outcomes, ${ }^{4}$ which often compromises the accuracy of judgements. Even in normal times, uncertainty can be so unnerving that people are often willing to pay more money, spend more time and incur greater pain to avoid making decisions with outcomes that cannot be easily weighted by the likelihood of occurring. ${ }^{6}$ Likewise, even when risks are more established (eg, a patient is told there is a $10 \%$ chance that her positive mammogram indicates cancer), people's experiences, biases and emotional responses to risk information may lead them to inflate their perceived likelihood of negative consequences.

Since negative feelings associated with uncertainty can amplify perceived risk, people may overestimate the prospect of bad outcomes well into the future. ${ }^{7-9}$ Risk perceptions related to COVID-19 are influenced by several factors and varying degrees of certainty, including personal experience with the virus, individualistic and prosocial values, communications from friends and family, trust in government, science and medical professionals, personal 
knowledge of government strategy and personal and collective efficacy. ${ }^{10}$ Not knowing the likelihood of contracting the novel coronavirus, or consequently becoming ill with COVID-19, may lead people to inflate perceived coronavirus-related risks relative to the more known risks associated with avoiding medical care for unrelated conditions. Furthermore, an inability to align judgements across health ailments can be dangerous-if not deadly-if it prevents patients from receiving treatment for conditions that may be far more dangerous to their health than COVID-19. ${ }^{11}$

Fear of COVID-19 pits some patients' need to receive preventive, elective or urgent care against the uncertainty of contracting the unpredictable pathogen. Thoughtful leadership should recognise the importance of helping people properly calibrate and contextualise risk and uncertainty to prevent additional strain on healthcare systems. Globally, there are increased concerns that health problems will worsen and become costlier to treat without timely detection. This is harmful to patients' health and has a detrimental impact on health systems that must balance overutilisation and underutilisation to smooth budget flows and revenue streams. Moreover, if the scourge of uncertainty spreads to healthcare workers, the resulting anxiety and fear may lower workplace satisfaction, productivity and overall well-being. ${ }^{12}$ Indeed, striking the right balance between providing treatment and mitigating risk and uncertainty is one of today's biggest healthcare challenges. It is especially so for those in leadership roles whose balancing act includes patient and employee health, in addition to the fiscal management of healthcare systems that have suffered financially from the pandemic. ${ }^{13}$

\section{MORE ACCURATE RISK PERCEPTION BENEFITS PATIENTS AND HEALTHCARE WORKERS}

Although physical distancing measures protect patients and employees from the virus, the necessary physical isolation may increase online exposure to misinformation and politicised facts that negatively impact decision-making. ${ }^{14} 15$ Research has shown that inaccurate risk information both taints risk perceptions and leads to poor decisions, and extensive use of technology is associated with decreased tolerance of uncertainty. ${ }^{16}$ This intolerance further disrupts patients' decisions to seek medical care or comply with health recommendations through distorted risk perceptions. To that end, healthcare leaders are obliged to help their patients and workers by effectively communicating known risk information and setting boundaries around the probabilities that remain unclear. This strategy can temper the negative emotional response that characterises these risky and uncertain times. ${ }^{17}$ Leaders can achieve this and relieve the fears of their constituents in three important ways: by promoting reliable information from trusted sources, communicating clear and accurate costs and benefits and gaining trust through transparency.

\section{Reliable information from trusted sources}

Where possible, healthcare leaders should review, use and promote best practices for safe clinical visits outlined by trusted health organisations (eg, WHO, National Health Service). These include adherence to NPIs such as physical distancing and mask wearing, as research shows that the perceived effectiveness of NPIs to reduce the risk of transmission is one of the greatest predictors of adherence to NPI guidelines. ${ }^{18}$ Moreover, people are more likely to accept outcomes associated with risk and uncertainty when the procedures leading up to them are perceived as well reasoned and fair. ${ }^{19}$ By establishing a record that organisational decisions flow directly from evidenced-based recommendations, people are more likely to comply because they understand the process by which the decisions were made.

\section{Clear and accurate costs and benefits}

Leaders should acknowledge that while the known risks and benefits of receiving necessary care cannot be directly compared with the uncertainty of contracting the coronavirus or suffering severe COVID-19 symptoms, the evidence suggests the latter is relatively rare. While health professionals often feel confident making recommendations with this knowledge, patients may not. For example, in a survey of patients at Vanderbilt University Medical Center, ${ }^{20}$ where $55 \%$ of respondents reported delaying medical care during the pandemic, the highest stated fear was contracting the virus from other patients. Leaders might assuage such uncertainty-related anxiety and heightened patient fears by promising NPI-compliant facilities that greatly reduce the likelihood of transmission and can ultimately encourage patients to seek necessary care.

Although people often rely on faulty intuitions over objective reasoning and facts when making judgements involving risk and uncertainty, strategies derived from behavioural economics can help people reason more accurately. ${ }^{21}$ For example, simply describing the risk of getting seriously ill from coronavirus in terms of frequencies (eg, per 100 patients) rather than percentages leads to a better understanding of risk, particularly among low numeracy individuals who often benefit from simplified framing. ${ }^{22} 23$ This approach illuminates that while, for many patients, there is variability in the likelihood of contracting the virus and becoming ill in an NPI-compliant clinical setting, that likelihood is within a range that remains quite low compared with the known risk of a serious health incident due to the failure to seek treatment for a new or pre-existing condition.

\section{Trust through transparency}

Transparency is crucial to maintaining organisational trust and managing expectations, including those involving risk and uncertainty. This is especially true when communicating bad news, such as when employees test positive or become ill with COVID-19. In a notable case, JPMorgan Chase violated its employees' trust by limiting notifications that a worker tested positive to employees working on the same floor or who came in direct contact with the infected coworker. ${ }^{24}$ This meant that the remaining employees learnt of cases through the news and social media. Although leadership may have covered their bases by notifying only those most squarely at risk, many employees felt the notifications should have been more broadly communicated by the organisation. In part, this dissatisfaction stemmed from transmission rate uncertainty, as being exposed to someone who is infected raises the likelihood of infection by an unknowable amount, and that uncertainty is unsettling. Consequently, withholding this information undermined trust in the organisation's leadership and represented a missed opportunity to help workers understand or process elevated risk perceptions. ${ }^{25}$ As with procedural fairness, transparency has many benefits to organisations ${ }^{26}$ which include greater employee trust in decisions. ${ }^{27}$ As such, we recommend that leaders build and maintain trust through operational transparency and by implementing strategies that quickly reduce risk-related anxiety when the crisis hits close to home.

\section{USE NORMATIVE INFORMATION TO HELP PEOPLE MANAGE} UNCERTAINTY AND CHANGE BEHAVIOUR

Once an organisation effectively communicates information about risk and uncertainty to help patients and healthcare 
workers accurately weigh the costs and benefits of seeking care, they can facilitate seeking necessary treatment (in facilities that adhere to best practices) through their messaging. One strategy for persuasive messaging is sharing normative information, which sets expectations for 'normal' behaviour by describing the positive behaviours of other patients. ${ }^{28}$ Normative information can help people manage uncertainty by allowing them to calibrate their risk relative to that of similar others. Although this does not alter the actual risks, knowing how other people manage them can help patients be more confident that their own actions are safe and acceptable.

When appropriate, healthcare leaders can communicate the social norm that similarly situated patients are seeking necessary care, ${ }^{29}$ as this is a long-known and effective strategy for persuasion. ${ }^{30}$ Framing persuasive messages can be achieved with social proof, which signals that the recommended course of action is indeed the most popular, ${ }^{31}$ or with defaults, which can indirectly convey that a preselected option is recommended. ${ }^{32}$ These simple strategies have been remarkably effective in increasing influenza shot acceptance, an important defence in limiting the strain on healthcare systems during the pandemic. Research has shown that organisations that set vaccination as the default (but allow employees to opt out) can expect higher compliance than those relying on employees to opt in. ${ }^{33}$

As an example of the social norm power of defaults, we look to our organisation, Duke University, and its efforts to increase influenza shot uptake among employees in the 2020 influenza season. During the pandemic, influenza shots were required University-wide for continued access to all campus buildings (ie, not just at the Medical Center, where influenza shots have always been mandatory). Duke employees could opt out, but only if they went so far as to obtain a verified medical or religious exemption, a structural design that preserved freedom of choice but required everyone to take action. For most, getting the influenza shot (ie, compliance) was the easiest path. Presenting vaccination as the default also sent a clear signal that getting the influenza shot was a norm that the University endorsed. Communicating this normative information reduces uncertainty and, combined with the added friction-filled steps for those who try to avoid the advocated behaviour, effectively increased uptake. ${ }^{34}$

Implementing these strategies from behavioural economics has implications beyond employee health. For example, widespread adoption of the influenza vaccine among Duke's workforce can help healthcare providers parse the signal from the noise when someone presents with overlapping symptoms of influenza and COVID-19. Moreover, since the influenza shot was distributed to a largely remote workforce, the required logistics and coordination produced insights that will inform the impending delivery of the coronavirus vaccines. Such 'practice runs' help leadership identify distribution challenges and assess how risk and uncertainty contribute to vaccine hesitancy, which may threaten adoption and prolong the crisis. ${ }^{35} 36$

\section{BEHAVIOURAL ECONOMICS STRATEGIES CAN HELP PATIENTS STAY HOME WHEN IN-PERSON CARE IS UNADVISABLE}

Deciding whether to seek care may not be an easy deliberation, and in some cases patients are safer at home. Just as healthcare leaders can use behavioural economics to nudge patients towards necessary in-person care, they can also use it to treat vulnerable patients at home when the chances of becoming seriously ill from COVID-19 exposure at a medical facility exceed those of postponing treatment or watchful waiting. Indeed, one silver lining of the coronavirus pandemic is the opportunity for healthcare leaders to explore cost-effective remote technologies that reduce non-essential in-person visits. Although innovation in medicine can often be mired down by regulation and competing interests, the current crisis has made 'digital first' a critical new default in healthcare delivery. Like defaults that convey normative information about what an organisation or policymaker believes is the best course of action, establishing remote care as the firstline treatment reduces the risk and uncertainty associated with seeking treatment.

As noted earlier, behavioural economics has shown that changing defaults can be a simple way to overcome status quo bias, or the general reluctance to stray from established practices. Since COVID-19 makes in-person healthcare (the prepandemic status quo) both riskier and more uncertain for everyone, many healthcare systems have updated their first-line treatment default to remote options, while in-person visits are scheduled only when truly necessary. The system-wide disruption caused by the pandemic presented an opportunity to reduce the friction that often interferes with organisations' ability to implement strategies, such as changing defaults, that reliably produce behaviour change. ${ }^{37}$ For example, switching to digital health technologies and delivering prescriptions by mail are default-switching strategies that successfully reduced unnecessary in-person care, and its associated risks and uncertainty, during the pandemic.

\section{Digital health technologies}

Before the coronavirus pandemic, the broad adoption of digital health technologies such as telemedicine was slowed by concerns over liability and reimbursement. However, healthcare systems can now accelerate their us ${ }^{38}$ in the name of public health. Digital health benefits go beyond the pandemic-related safety of patients and healthcare workers, with the potential to enhance patient-provider communication $^{39}$ and provide greater convenience with little to no cost increase. Enabling providers to take advantage of automation, for example, helps fill communication gaps between in-person visits and enables better patient self-management of both chronic and acute conditions. As digital health technologies become more sophisticated, they can incorporate a behavioural design approach that uniquely matches behavioural interventions to personalised patient needs via programmes that respond to user properties, biometric measurements, survey responses or task adherence. Indeed, there is great potential for physicians to integrate behavioural economics solutions into their clinical workflows and prescribe behaviourally informed digital health programmes to their patients to help manage their care at home. ${ }^{40}$

\section{Prescriptions delivered by mail}

As people largely avoid retail settings, the pandemic produced greater reliance on mail-order prescriptions. Patients who receive prescriptions by mail are generally more compliant and pay less out of pocket than those purchasing retail prescriptions. ${ }^{41}$ The frictionless convenience of mail-order and ability to enact automatic refills leads to higher initial fill rates among patients and to greater medication adherence over time. ${ }^{42}$

Although some patients and providers may revert to in-person healthcare delivery once the pandemic passes, others will simply stick with the new defaults, such as telemedicine and mail-order prescriptions, because they have become accustomed to them or the newer alternatives are more efficient, effective and economical. Indeed, the Centers for Medicare \& Medicaid Services has permanently expanded coverage of more than 60 telehealth services ${ }^{43}$ in 
recognition that digital care is essential during the pandemic and well beyond.

\section{FIRST, DO NO HARM}

While the underutilisation of healthcare services due to COVIDrelated safety concerns is alarming, the disruption presents an opportunity for healthcare systems to identify trends of overutilisation. For example, examining claims for services that were delayed or discontinued during the pandemic may reveal that some provided limited clinical benefit at exceedingly high cost or, worse, produced harm. ${ }^{44} 45$ Likewise, the rapid adoption of hygiene practices likely had the secondary benefit of reducing the transmission of other airborne viruses and bacterial infections that often complicate patient care and recovery. Given that many patients acquire complications and even die of preventable secondary infections, organisations can take advantage of the current health crisis to update their best practices and reduce the spread of all infections.

\section{CONCLUSION}

The vaccine delivery phase of the pandemic remains a time of continued risk and uncertainty. As we await more widespread distribution and better learn how to treat COVID-19 cases, healthcare leaders can leverage insights from behavioural economics to help patients and workers manage the risk and uncertainty that is now woven into the fabric of daily life. As they impose safeguards that minimise transmission rates in the workplace, many also realise that keeping everyone safe is only one of many hurdles to keeping people healthy and productive. An empathetic approach to how people interpret information about risk and uncertainty, and how they respond to strategies such as defaults and social norms, can lead to better outcomes in patient health, employee safety and well-being and overall health system utilisation. Leaders who reduce some of the uncertainty that concomitantly circulates with the virus, whether real or perceived, can help nudge people towards better decisionmaking and result in better outcomes for everyone.

Twitter Janet Schwartz@JanetASchwartz and Aline Holzwarth @alineholzwarth

Acknowledgements The authors are grateful to the associate editor and two anonymous reviewers for their feedback on an earlier version.

Contributors $\mathrm{JS}$ and $\mathrm{AH}$ conceptualised the idea, conducted the relevant literature review and wrote the paper. Both authors accept full responsibility for the content.

Funding The authors' work was supported by their employer, Duke University.

Competing interests None declared.

Patient consent for publication Not required.

Provenance and peer review Not commissioned; externally peer reviewed.

Open access This is an open access article distributed in accordance with the Creative Commons Attribution Non Commercial (CC BY-NC 4.0) license, which permits others to distribute, remix, adapt, build upon this work non-commercially, and license their derivative works on different terms, provided the original work is properly cited, appropriate credit is given, any changes made indicated, and the use is non-commercial. See: http://creativecommons.org/licenses/by-nc/4.0/.

ORCID iD

Janet Schwartz http://orcid.org/0000-0001-7297-4283

\section{REFERENCES}

1 Loewenstein G, Hagmann D, Schwartz J, et al. A behavioral blueprint for improving health care policy. Behav Sci 2017;3:52-66.

2 Kahneman D, Tversky A. Prospect theory: an analysis of decision under risk. Econometrica 1979;47:263.

3 Fischhoff B, Davis AL. Communicating scientific uncertainty. Proc Natl Acad Sci U S A 2014;111:13664-71.

4 Anderson EC, Carleton RN, Diefenbach M, et al. The relationship between uncertainty and affect. Front Psychol 2019;10:2504.
5 Smithson M. Psychology's ambivalent view of uncertainty. Uncertainty and risk: Multidisciplinary perspectives, 2008: 205-17.

6 Lovallo D, Kahneman D. Living with uncertainty: attractiveness and resolution timing. J Behav Decis Mak 2000:13:179-90.

7 Johnson EJ, Tversky A. Affect, generalization, and the perception of risk. J Pers Soc Psychol 1983;45:20-31.

8 DeSteno D, Petty RE, Wegener DT, et al. Beyond valence in the perception of likelihood: the role of emotion specificity. J Pers Soc Psychol 2000;78:397-416.

9 Lerner JS, Keltner D. Fear, anger, and risk. J Pers Soc Psychol 2001;81:146-59.

10 Dryhurst S, Schneider CR, Kerr J. Risk perceptions of COVID-19 around the world. J Risk Res 2020:1-13.

11 Woolf SH, Chapman DA, Sabo RT, et al. Excess deaths from COVID-19 and other causes, March-April 2020. JAMA 2020;324:510-3.

12 Gillespie N, Searle R, Gustafsson S. Preserving employee trust during crisis. Behav Sci 2020:1-10.

13 Mellnick T, Karklis L, Tran AB. Americans are delaying medical care, and it's devastating health-care providers. The Washington Post, 2020. Available: https://www. washingtonpost.com/nation/2020/06/01/americans-are-delaying-medical-care-itsdevastating-health-care-providers/ [Accessed 2 Jun 2020].

14 Pennycook G, McPhetres J, Zhang Y, et al. Fighting COVID-19 misinformation on social media: experimental evidence for a scalable accuracy-nudge intervention. Psychol Sci 2020;31:770-80.

15 Reyna VF. A scientific theory of GIST communication and misinformation resistance, with implications for health, education, and policy. Proc Natl Acad Sci U S A 2020;7:201912441.

16 Rozgonjuk D, Elhai JD, Täht $K$, et al. Non-social smartphone use mediates the relationship between intolerance of uncertainty and problematic smartphone use: evidence from a repeated-measures study. Comput Human Behav 2019:96:56-62.

17 Lerner JS, Li Y, Valdesolo P, et al. Emotion and decision making. Annu Rev Psychol 2015:66:799-823

18 Broomell SB, Chapman GB, Downs JS. Psychological predictors of prevention behaviors during the COVID-19 pandemic. Behavioral Science Policy 2020:1-8 https://behavioralpolicy.org/articles/psychological-predictors-of-prevention-behaviorsduring-the-covid-19-pandemic

19 De Cremer D, Tyler TR. The effects of trust in authority and procedural fairness on cooperation. J Appl Psychol 2007;92:639-49.

20 Shriji Patel MD, Lorenzi N. Critical insights from patients during the Covid-19 pandemic. NEJM Catalyst. 2020 https://catalyst.nejm.org/doi/full/

21 Slovic P. Peters E. Risk perception and affect. Curr Dir Psychol Sci 2006:15:322-5

22 Peters E, Västfjäll D, Slovic P, et al. Numeracy and decision making. Psychol Sci 2006:17:407-13.

23 Lipkus IM, Peters E. Understanding the role of numeracy in health: proposed theoretical framework and practical insights. Health Educ Behav 2009;36:1065-81.

24 CNBC. JPMorgan traders complain that bank doesn't inform all staff of coronavirus cases at headquarters, 2020. Available: https://www.cnbc.com/2020/09/23/ jpmorgan-traders-complain-that-bank-doesnt-inform-all-staff-of-coronavirus-cases-atheadquarters.html

25 Tham K, Lu Q, Teo W. Infodemic: what physician leaders learned during the COVID-19 outbreak: a qualitative study. BMJ Leader 2020;0:1-6.

26 Ariely D, Holzwarth $A$. The choice architecture of privacy decision-making. Health Technol 2017;7:415-22.

27 Rawlins BR. Measuring the relationship between organizational transparency and employee trust. Public Relations Journal 2008;2:1-21.

28 Liao JM, Pronovost PJ, Navathe AS. To Re-Open health care, leaders should address patient fears. NEJM Catalyst 2020 https://catalyst.nejm.org/doi/full/

29 Broomell SB, Chapman GB, Downs JS. Psychological predictors of prevention behaviors during the COVID-19 pandemic. Behav Sci 2020:1-8 https:// behavioralpolicy.org/articles/psychological-predictors-of-prevention-behaviors-duringthe-covid-19-pandemic

30 Schultz PW, Nolan JM, Cialdini RB, et al. The constructive, destructive, and reconstructive power of social norms. Psychol Sci 2007;18:429-34.

31 Cialdini RB. Influence: The psychology of persuasion. New York: Collins, 2007: 55. 339

32 Everett JAC, Caviola L, Kahane G, et al. Doing good by doing nothing? the role of social norms in explaining default effects in altruistic contexts. Eur J Soc Psychol 2015:45:230-41

33 Chapman GB, Li M, Colby $\mathrm{H}$, et al. Opting in vs opting out of influenza vaccination. JAMA 2010;304:43-4.

34 Jachimowicz JONM, Duncan S, Weber EU, et al. When and why defaults influence decisions: a meta-analysis of default effects. Behav Public Policy 2019;3:159-86.

35 Gallup. One in three Americans would not get COVID-19 vaccine, 2020. Available: https://news.gallup.com/poll/317018/one-three-americans-not-covid-vaccine.aspx

36 Clark J. How to increase flu vaccination during the COVID-19 pandemic, health affairs Blog 2020.

37 Brewer NT, Chapman GB, Rothman AJ, et al. Increasing vaccination: putting psychological science into action. Psychol Sci Public Interest 2017;18:149-207.

38 CMS.gov. Medicare telemedicine health care provider fact sheet. Baltimore US: Centers for Medicare \& Medicaid Services, 2020. https://www.cms.gov/newsroom/ fact-sheets/medicare-telemedicine-health-care-provider-fact-sheet 
39 Wherton J, Shaw S, Papoutsi C, et al. Guidance on the introduction and use of video consultations during COVID-19: important lessons from qualitative research. BMJ Leader 2020;4:120-3.

40 Agarwal A, Patel M. Prescribing behavior change: opportunities and challenges for clinicians to embrace digital and mobile health. JMIR Mhealth Whealth 2020;8:e17281

41 Hopkins J. Wall Street Journal, 2020. Available: https://www.wsj.com/articles/mailorder-drug-delivery-rises-during-coronavirus-lockdowns-11589281203

42 Fernandez EV, McDaniel JA, Carroll NV. Examination of the link between medication adherence and use of mail-order pharmacies in chronic disease states. J Manag Care Spec Pharm 2016;22:1247-59.
43 CMS.gov Trump administration Finalizes permanent expansion of Medicare telehealth services and improved payment for time doctors spend with patients, 2020. Available: https://www.cms.gov/newsroom/press-releases/trump-

administration-finalizes-permanent-expansion-medicare-telehealth-services-andimproved-payment

44 Anderson GF, Reinhardt UE, Hussey PS, et al. It's the prices, Stupid: why the United States is so different from other countries. Health Aff 2003;22:89-105.

45 Jauhar S. People have stopped going to the doctor. most seem just fine, 2020. Available: https://www.nytimes.com/2020/06/22/opinion/coronavirus-reopenhospitals.html 